\title{
The concept of social risks perception
}

\author{
K. Kampová \\ Department of Security Management, Faculty of Special Engineering, \\ University of Žilina, Slovakia
}

\begin{abstract}
The purpose of this paper is to present an approach of structural perception of risks associated with human security, which is based on the research carried out at the Faculty of Special Engineering, University of Zilina. The risks relating to human security have a specific nature, which is based in their consequences impacting simultaneously on both humans personally and on the whole of society. Therefore, such risks are distinctive by the two forms they can be perceived in - individual and societal. Generally, we refer to these risks as social risks. The presented concept of social risk perception provides a fundamental theoretical framework, which is the precondition of understanding the background of social risk complexity. Social risk and its perception are important concepts for national and regional policies, because the understanding of how people and the broader community perceive risk contributes to successful social risk analysis and consecutively to developing effective measures for reducing or eliminating of social risks.
\end{abstract}

Keywords: human security, social risks, quantitative methods, uncertainty, model.

\section{Concept of human security and social risk}

The increasing interconnectivity within trade, finance, technology, communications, and population mobility has created impacts on citizens across the globe, which may be difficult or impossible for states to regulate. Therefore, besides national security and technical security, the complex understanding of security has been recently emphasizing the threats impacting human. We commonly refer to this dimension of the conceptual understanding of security as a human security. 
The concept of human security was first systematically elaborated and gained wide recognition from the UNDP's Human Development Report in 1994, where human security has been explained as an individual feeling of safety without fear and deficiency. The report has characterized human security by four essential attributes [13]:

- Human security is a universal concern. This means that there are many threats (unemployment, drugs, crime, pollution and human rights violations) impacting people regardless the place they live. Even though, the intensity of these threats may differ depending on various factors, they are real and present all around the world.

- The components of human security are interdependent. The threats associated with human security are not isolated. They are related to various types of social processes and their consequences are often not confined within national borders.

- Human security is easier to ensure through early prevention than later intervention. When reducing the intensity of threats and their impacts, it is more costly to utilize repressive measures rather than preventive ones.

- Human security is people centred. Human security is assessed by people's perception of how they live and feel about their freedom and possibilities of social opportunities.

Human security introduces a number of new elements to traditional security paradigm. The basic objective of human security is to provide protection to people rather than protection of territory. Thus, the human security focuses on individuals and not only on nations. Human security considers the dynamic system with processes and situations that are subject to change during certain period of time and as such is uncertain. On the contrary, the traditional security draws attention to structural interpretation of threats by executive branches of state.

There are two main aspects noticeable when describing human security. The first one focuses on chronic threats as hunger, diseases or poverty. The second one outlines the human security as a way of protection from sudden disruptions in the pattern of daily life. The latter is the main reason of introducing the uncertainty considerations into the concept of human security. Thus, for the purpose of this paper, we will consider human security in context of sudden and unpredictable events impacting everyday's life of people.

In general, the term "security" often comes along with the term "risk". Security is commonly interpreted as a situation with risk minimized to an acceptable level. This relation however does not provide an explanation what risk actually means. Risk is a part of almost every human activity and hence it is frequently understood intuitively. Situations, in which people perceive risk, have certain common elements. The first one is that people do not know what will happen. The second one is that the personal interests are exposed to consequences in such situations.

Risks associated with human security are generally called social risks. The specific characteristic of these risks is that their consequences harm individual 
people of society as well as the society as a whole. Thus, impacts as an important dimension of social risk define two different forms of social risk - societal and individual. Individual form of social risk contains elements of subjectivity, based on perception of social risk through the harm potentially implied to people personally. On the other hand, societal form of social risk represents the public perception of impacts on individual interests exposed to the risk. In general, the individual form provides insight into complexities of public perception of social risks, but it does not allow us to analyze these risks, as the meaningful quantification of social risk can be only made within the societal form.

\section{Individual perception of social risks}

Individual form of social risk represents a perception of the risk in aspect of individual's interest exposed to the adverse consequences of these risks. The elements of subjectivity are brought into the perception of social risks by the harm potentially implied to people personally. These elements are the basis for different intensity of social risk perceived by different people. Therefore, the level of individual form of risk might be different for each individual as it is specific. The intensity of individual form is determined by different factors, which can be generally classified into three levels [5]:

- personal,

- institutional,

- cultural.

These levels represent the individual attributes constituting the societal dimension of human life. Every individual is influenced by own immediate personal predispositions including physical and psychical characteristic, gender, age, education, income, etc. The institutional level involves in the human life by political system, social welfare, law enforcement, etc. The cultural level reflects the cultural norms, religion, beliefs, nationality etc.

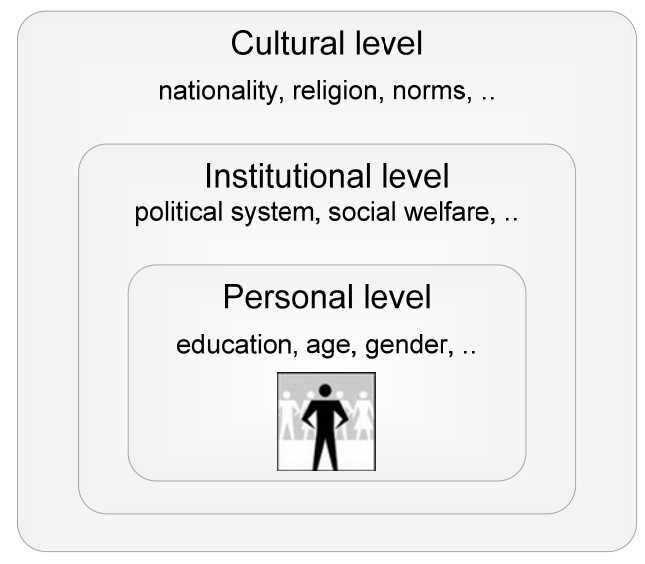

Figure 1: Classification of social risk factors. 
Culture is a characteristic phenomenon of mankind, which has a strong fundamental influence on the way people think, act, behave and develop. Culture is usually interpreted as the way of people live. Social risk factors on cultural level represent the highest level influencing the individual perception of social risk. From the individual's perspective, the factors of cultural level express an environment in which the individual lives and which has to abide by or at least be aware of.

One of the most familiar definitions of the concept of culture is offered by British anthropologist Edward B. Taylor [10]: "Culture is that complex whole which includes knowledge, belief, art, morals, law, customs and other capabilities and habits acquired by man as a member of society." Thus, the understanding of culture should not be constrained only to an art or music, as we sometimes narrow this concept, but culture chiefly involves standards and values which form our social life, our cognizance of good and evil, our religion, etc. There are three basic areas of culture [8]:

- religious,

- national,

- individual social groups.

Religious area represents common culture which is embedded in fundamental ideas and values of individual religions. Religious dimension of cultural level includes elements, which have a significant effect to perception of social risks; however this effect has highly individual character. National area of culture is the area with deep historical background. The nation is a vast community, in which each subject has common goals and ambitions - national interest. The national area of cultural level affects the individual perception of social risks by the factors as common territory, language, political beliefs, economics, social conditions, etc. Area of individual social groups represents the perception of culture by the social units, the unique features of which make them distinguishable from other units of the same type. Typical examples of social groups are family, youth or various associations. The identification of significance of the area's impacts on the level of individual form of social risk and its perception requires the characterization of social groups in which the individual is involved.

Institutional level is characterized by the socio-political system, which is based on various relations. Social relations are not formed unrestrainedly or chaotically, but it is necessary to control them. These relations are controlled by the social institutions. Social institutions exist in every society and serve as a tool, which society employs to achieve required behaviour of its members. Institutions have the capabilities to develop a social pressure on individuals but also on different social groups and hence the social institutions have a coercive nature. In this sense, social institutions are formed by a set of social rules, which affect prescriptively on social behaviour of human (e.g. norms, values, sanctions, ideals, behavioural patterns, etc.). Effectively, the institutions create socially accepted scope, in which the needs of society members are fulfilled and the objectives of society are accomplished. The respect of this scope is the main precondition supporting the sustainable management of social risks. Despite 
common acceptance of social institutions on societal level, the individual perception of them might be different. Therefore, the institutional level is the source of many significant factors, which influence the individual form of social risk.

Personal level involves specific natural characteristics and salient traits of human, which are based on inherited genetic preconditions and physical, psychological and learned characteristics. The immediate personal characteristics complement the factors of individual perception of social risks. These factors are presented in a common manner the individual behave and act within the social system and show us the humans in their essence. There are two types of individual's traits, which we consider when identifying the personal factors of individual perception:

- inherited traits,

- learned traits.

Inherited traits form the innate nature of human, in which the congenital characteristics are expressed; this group of factors includes gender, temperament, etc. On the contrary, learned traits come through the acquired behaviour, which is conditioned response to inducements through either voluntary or involuntary in-tent. The factors, which are acquired during human's life and influence individual perception include education, various knowledge, employment, financial situation, etc.

Outlined levels of social risk factors define the elements determining the human uniqueness within the socio-cultural practice. The elements on different levels are not isolated and they depend on mutual relations between these levels. Therefore, the individual perception of social risk is set by the combination of elements on each level. Individual form of social risk provides a perspective on social risk, through which we are able to analyze various risk factors influencing the existence and intensity of social risk. Definition of relevant factors of social risks is one of the main objectives of social risks identification within the process of risk management and the individual form of social risk help us to understand the conceptual background of connections between occurring social risk and its determining factors.

\section{Societal perception of social risks}

Unlike the individual form, societal form of social risk represents the perception of social risk in the context of society. Societal perception provides a possibility of studying social risks and their impacts on societal interests with respecting their individual character at the same time. Societal form of social risk thus poses the objective perception of risks occurring in societal environment, expressing the perspective of particular society or state on the existence and intensity of social risks impacting their members.

Societal form of social risk does not occur isolated and each particular social risk has always its individual form as well as societal form. A way the societal form is perceived depends on the character of social risk in its individual form. The individual consequences of social risk perceived in aspect of whole society 
define a relation between both forms of social risk. Accordingly, we may distinguish between two types of societal perception of social risk:

- continuous,

- discrete.

The societal perception of continuous social risk has a stateful character. That means the individuals suffering from impacts of social risk occur in particular negative state or situation for a specific period of time. The common continuously perceived social risks include unemployment, homelessness, poverty, or drug addiction. The discrete societal perception of social risk qualifies the risks as stateless. Such perception considers the discrete occurrence of specific adverse event more important than the continuous consequences of this event. The typical examples of discretely perceived social risk are various kinds of monitored criminality.

The importance of societal form of social risks is that it exposes the relations and dependencies between different factors determining the social risk and thus reveals the societal context of social risk. Subsequently, understanding the context of social risk helps us to take adequate measures and reduce the intensity of the risk. The societal perception of social risks has essential meaning for the process of social risk management, because it provides the quantification capabilities of social risk. The main aim of the social risk quantification is to numerically define the intensity of risk, i.e. to determine the frequency of social risk occurrence and gravity of its impact. There are two types of the social risk quantification:

- relative quantification,

- absolute quantification.

The relative quantification expresses the risk by a value, which is proportional to selected or defined base [12]. The relative quantification of social risk is based on continuous perception of social risks. The intensity of social risk is represented by a part of society who is affected by consequences of social risk compare to whole society. In this case the level of social risk is constant at the specific time and it is commonly quantified in percents. By the relative quantification we define frequency of continuous consequences in discrete time (see Figure 2).

Figure 2 shows an illustrative social group consisting of 3 people. The relative quantification means, that the social risk is perceived at selected discrete moments (e.g. unemployment rate can be reported at the end of each month). The perception of social risk is in this case continuous and therefore we are able to determine the status of every member of analyzed society. The individual is either in situation harmed by the consequences of social risk or not. Particularly on Figure 2, we have monitored the status of the social group at times t1..t4. The quantified level of social risk perceived on societal level is successively $66 \%$, $66 \%, 100 \%$ and $33 \%$. These values are of course clearly illustrative and the actual social risk analysis considers more extensive social groups, the principle, however, remains the same. 


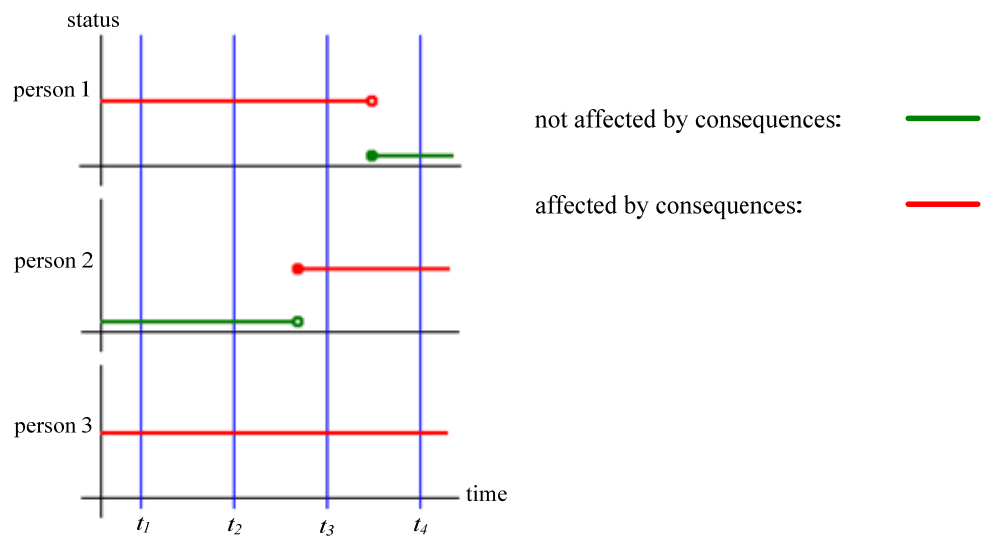

Figure 2: Relative quantification of social risks (source: author).

The absolute quantification presents the social risk by the frequency or probability of potential loss and is expressed by a particular metric, e.g. number of deaths. This type of quantification comes out from discrete perception of social risk. Thus, the level of social risk represents the number of occurrences of analysed negative event, which are observable during the particular period of time. The absolute quantification defines the discrete frequencies in the continuous time (see Figure 3).

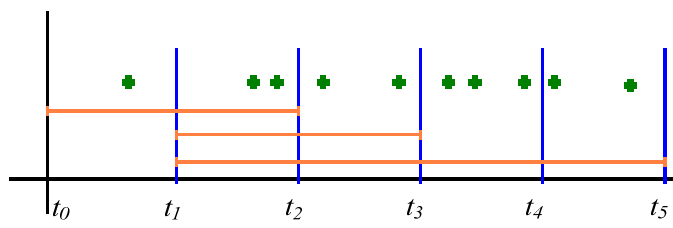

occurrence of event:

monitored time interval:

Figure 3: Absolute quantification of social risks (source: author).

Figure 3 shows the level of certain social risk analysed on continuous time intervals (red lines), in which the occurrence of negative event (green dots) is monitored. The discrete societal perception defines the intensity of social risk by the number of event occurrences in selected time interval. For example, the level of social risk in time interval $<\mathrm{t} 1, \mathrm{t} 3>$ is numerically expressed by frequency of 4 events.

The distinguishing between two types of societal perception of social risks is a chief precondition for quantification of social risks, which allows us to use different methods applicable within the process of their study. Described approach is a basis of quantitative analysis of social risk. There are wide range of exact and numeric methods, which can be employed within the analysis and help 
us to make qualified decision in order to ensure the intensity of social risk at acceptable level and thus to provide required level of human security within particular society.

\section{Conclusion}

The human security is a main precondition of satisfactory quality of human's life. Nevertheless, there are many threats which potentially disrupt the pattern of individual's everyday life. We refer to a chance of exposure of individual and societal interests to the adverse consequences of future events as social risk. These risks do not occur isolated but rather they take place in various relations, connections and aspects. The knowledge of structure of social risks, circumstances of their occurrence and development and way their consequences affect people is the basis for the concept of social risks perception. The presented theoretical framework of social risks perception is based on distinguishing between two forms of social risk - individual and societal. This approach facilitates the process of social risk identification and analysis and contributes to developing effective measures to reduce the intensity of social risks. The further research and development of this concept will be supported by the implementation of the EU's project called "eSEC - Competency Based e-portal of Security and Safety Engineering". This project is focused on the international information exchange and should help us to develop knowledge by employing broader experience and perspectives on the subject.

\section{Acknowledgement}

With the support of the Lifelong Learning Programme of the European Union, Project Competency Based e-portal of Security and Safety Engineering - eSEC, 502092-LLP-1-2009-1-SK-ERASMUS-EMHE."

\section{References}

[1] Aven T (2003) Foundation of Risk Analysis: A Knowledge and DecisionOriented Perspective. John Wiley \& Sons, Chichester.

[2] Damodaran A (2007) Strategic Risk Taking: A Framework for Risk Management. Whartoon School Publishing, New Jersey

[3] Fotr J (2006) Manažerské rozhodování. Postupy, metody a nástroje. Ecopress, Prague

[4] Holton GA (2004) Defining Risk. Financial Analysts Journal, 60, 19-25.

[5] Jaaber, RA, Dasgupta SD (2006) Assessing Social Risks of Battered Women. Praxis International. http://praxisinternational.org/files/ praxis/files/AssessingSocialRisk.pdf. Accessed 25 April 2010

[6] Liu Institute for Global Issues, University of British Columbia (2005) Human Security Report 2005, Oxford University Press. www.humansecurityreport.info Accessed 25 April 2010 
[7] Lovecek, Tomas; Ristvej, Jozef; and Simak, Ladislav (2010) "Critical Infrastructure Protection Systems Effectiveness Evaluation," Journal of Homeland Security and Emergency Management: Vol. 7 : Iss. 1, Article 34. DOI: 10.2202/1547-7355.1613, Available at: http://www.bepress.com/ jhsem/vol7/iss $1 / 34$

[8] Nový, I., Surynek, A. 2006. Sociologie pro ekonomy a manažery. Praha: Grada Publishing, 2006, str. 72, 82, 242. ISBN 80-247-1705-0.

[9] Prochazkova D et al (2007) Lidská bezpečnost. KKŘ , Policajní akademie České republiky v Praze, Prague.

[10] Sardar Z, Loon B (1997) Cultural Studies for Beginners. Icon Books, Cambridge.

[11] Slovic P (2000) The Perception of Risk. Earthscan, London

[12] Tichý M (2006) Ovládaní rizika. C.H. Beck, Prague.

[13] United Nations Development Programme (1994) Human Development Report 1994. Oxford University Press, New York. http://hdr.undp.org/en/reports/global/hdr1994/chapters/ Accessed 25 April 2010 . 